\title{
Frequency and Prognostic Impact of Consistently Low Edmonton Symptom Assessment System Score in the Patients Treated with Palliative Radiotherapy
}

\author{
Carsten Nieder ${ }^{1}$, Thomas A. Kämpe ${ }^{1}$ \\ 1. Dept. of Oncology and Palliative Medicine, Nordland Hospital Trust
}

$\square$ Corresponding author: Carsten Nieder, nieder_radonc_tum@hotmail.com

Disclosures can be found in Additional Information at the end of the article

\section{Abstract}

\section{Introduction}

Our department's standard work-flow includes assessment of all the patients with the Edmonton Symptom Assessment System (ESAS), a one-sheet questionnaire addressing 11 major symptoms and wellbeing on a numeric scale of zero-10, before the palliative radiotherapy (PRT). Based on previous research, we hypothesized that the patients with minimal or moderate total symptom burden might have better overall survival after the PRT than those with at least one higher symptom score.

\section{Methods}

We performed a retrospective analysis of 94 patients and calculated actuarial survival from the first day of the PRT (Kaplan-Meier method). We identified the patients with the score zero for all ESAS items (no symptoms), at least one item with score one-two (minimal symptoms), and at least one item with the score three (moderate symptoms).

\section{Results}

High proportions of the patients had ESAS scores zero- two for nausea (80\%), sadness/depression (65\%) and constipation (64\%). The mean values were often in the range of two-four. Only one patient reported scores of zero throughout the questionnaire. He was treated for hematuria, a symptom that is not part of the ESAS. Three patients reported scores of zero-two throughout the questionnaire. Except for the performance status zero-one, their baseline characteristics were heterogeneous. Two patients reported scores not exceeding three for all items. These patients had excellent performance status, too. None of the six patients

Received 12/20/2017 Review began 12/24/2017 Review ended 01/01/2018 Published 01/06/2018

\section{C) Copyright 2018}

Nieder et al. This is an open access article distributed under the terms of the Creative Commons Attribution License CC-BY 3.0., which permits unrestricted use, distribution, and reproduction in any medium, provided the original author and source are credited.
(6\%) with relatively low ESAS scores of zero-three received care by the hospital's multidisciplinary palliative team. Only one was using opioid analgesics. The median survival for this small subset of six patients was six months, identical to the result for all the patients with higher symptom burden $(\mathrm{p}=0.62)$.

\section{Conclusion}

The proportion of the patients with ESAS scores zero-three throughout the questionnaire was $6 \%$, which resulted in the limited statistical power for the survival comparisons. The survival outcomes were similar. Before PRT, $94 \%$ of the patients reported at least one ESAS item of severity four-10. The symptoms not included in the questionnaire, e.g., hematuria might result in erroneous assignment to the low-symptom-burden group and obscure the prognostic impact 


\section{Cureus}

of low ESAS symptom burden.

Categories: Radiation Oncology, Oncology

Keywords: palliative radiotherapy, edmonton symptom assessment system, prognosis, cancer, patientreported symptoms

\section{Introduction}

The Edmonton Symptom Assessment System (ESAS) is a short, one-sheet questionnaire addressing the well-being and the major symptoms, e.g., pain and nausea, on a numeric scale of zero-10 [1]. It has been employed in different clinical settings, including the registration of the patient-reported symptoms before the palliative radiotherapy [2-4]. The main purpose is to improve the clinical care, e.g., by adjusting medications and referring the patients to palliative care specialists, psycho-oncologists and other experts who might be able to enhance the quality of life [5-6]. Several aspects of the clinical research have also been addressed with this tool [78]. For example, the data suggest that ESAS scores provide prognostic information, mainly because severe symptoms are associated with shorter survival [9-10]. We hypothesized that the patients with minimal or moderate total symptom burden might have better overall survival after the palliative radiotherapy than those with at least one higher symptom score. In line with previous studies [11-12], we identified the patients with scores zero for all items (no symptoms), at least one item with score one-two (minimal symptoms), and at least one item with the score three (moderate symptoms). This study was performed to expand our ongoing efforts to develop prognostic models that support the decision making for personalized palliative approaches [13-15].

\section{Materials And Methods}

We performed a retrospective analysis of 94 patients who started the palliative radiotherapy during the time period between 2013-2015 and included the patients with the complete and incomplete treatment. The radiotherapy typically consisted of daily 3 Gray (Gy) or $4 \mathrm{~Gy}$ fractions or a single dose of $8 \mathrm{~Gy}$ fractions. The ESAS questionnaire was administered as part of our standard workup by a registered oncology nurse, before physician consultation and imaging for the treatment planning approximately one week before the radiotherapy. The statistical analysis was performed with the Statistical Package for the Social Sciences (SPSS) version 24 (IBM Corp., Armonk, New York). The actuarial survival was calculated from the first day of the radiotherapy (Kaplan-Meier method). Fifteen patients were still alive with a median follow-up of 18 months. The date of death was entered in the remaining 79 patients. The survival curves were compared by the log-rank test.

\section{Results}

Most patients were male, elderly and had prostate or lung cancer with distant metastasis. The bone metastasis was common treatment indication, however, $11 \%$ of the patients had the nonmetastatic disease and were treated for hematuria, dyspnea, and other local symptoms. Table 1 shows additional baseline characteristics.

\section{Variable}

ECOG performance status
No

$\%$
38

30 


\section{Cureus}

Gender

Primary tumor site

$\begin{array}{ll}\text { Prostate } & 28\end{array}$

Lung (small cell)

Lung (non-small cell)

Colorectal

Bladder

Malignant melanoma

Kidney

Others

RT target types ${ }^{1}$

Bone metastasis

Brain metastasis

Prostate or bladder

Others

Patients without metastatic disease

Systemic cancer treatment

No

Before RT

Opioid analgesics

No

Steroids

No 


\section{Cureus}

\section{TABLE 1: The baseline characteristics before the palliative radiotherapy.}

ECOG: Eastern Cooperative Oncology Group, RT: Radiotherapy, MPCT: multidisciplinary palliative care team.

Some patients were treated with more than one target.

As shown in Table 2, high proportions of the patients had ESAS scores zero-two (no or minimal symptoms), for nausea (80\%), sadness/depression (65\%) and constipation (64\%). The mean values were often in the range of two-four.

\begin{tabular}{|l|lll|}
\hline Item & Mean & Range & $\%$ 0-2 \\
\hline Pain (not moving) & 3 & $0-9$ & 50 \\
Pain (while moving) & 4 & $0-10$ & 34 \\
Fatigue & 4 & $0-10$ & 39 \\
Nausea & 1 & $0-8$ & 80 \\
Dyspnea & 3 & $0-10$ & 55 \\
Dry mouth & 3 & $0-10$ & 50 \\
Appetite & 4 & $0-10$ & 45 \\
Constipation & 2 & $0-10$ & 64 \\
Anxiety/restlessness & 3 & $0-10$ & 56 \\
Sleep & 3 & $0-10$ & 53 \\
Sadness/depression & 2 & $0-10$ & 65 \\
\hline Overall wellbeing & 4 & $0-10$ & 37 \\
\hline
\end{tabular}

\section{TABLE 2: The Edmonton Symptom Assessment System (ESAS) before the palliative} radiotherapy.

ESAS zero on a scale from zero-10 with no symptoms.

Only one patient reported scores of zero throughout the questionnaire. He was treated for hematuria, a symptom that is not part of the ESAS. Three patients reported scores of zero-two throughout the questionnaire. Except for the performance status zero-one, their baseline characteristics were heterogeneous, as shown in Table 3. 


\section{Cureus}

\begin{tabular}{|c|c|c|c|c|}
\hline Patient nr. & $\begin{array}{l}\text { Gender, age, } \\
\text { PS }\end{array}$ & Tumor type, metastases & $\begin{array}{l}\text { Target volume, } \\
\text { dose }\end{array}$ & $\begin{array}{l}\text { Chemotherapy, analgesics, } \\
\text { steroids }\end{array}$ \\
\hline $\begin{array}{l}1 \text { (all items } \\
0 \text { ) }\end{array}$ & $\begin{array}{l}\text { Male, 83, PS } \\
2\end{array}$ & $\begin{array}{l}\text { Bladder cancer, lung/bone } \\
\text { met. }\end{array}$ & Bladder (3 Gy x10) & $\begin{array}{l}\text { No CTx, no opioid analgesics, no } \\
\text { steroids }\end{array}$ \\
\hline 2 (max. 2) & $\begin{array}{l}\text { Female, 67, } \\
\text { PS } 0\end{array}$ & Breast cancer, 4 organs & $\begin{array}{l}\text { Whole brain ( } 2.5 \mathrm{~Gy} \\
\mathrm{x} 15)\end{array}$ & CTx, no opioids, steroids \\
\hline 3 (max. 2) & $\begin{array}{l}\text { Male, 74, PS } \\
1\end{array}$ & Colon cancer, 4 organs & Bone (3 Gy x10) & CTx, opioids, no steroids \\
\hline 4 (max. 2) & $\begin{array}{l}\text { Male, 75, PS } \\
0\end{array}$ & Rectal cancer, 3 organs & Bone (3 Gy x10) & CTx, no opioids, no steroids \\
\hline 5 (max. 3) & $\begin{array}{l}\text { Female, 60, } \\
\text { PS } 0\end{array}$ & NSCLC, brain only met. & $\begin{array}{l}\text { Whole brain ( } 2.5 \text { Gy } \\
\text { x15) }\end{array}$ & CTx, no opioids, no steroids \\
\hline 6 (max. 3) & $\begin{array}{l}\text { Male, 70, PS } \\
0\end{array}$ & Mesothelioma, not met. & $\begin{array}{l}\text { Thoracic wall (3 Gy } \\
x 12)\end{array}$ & CTx, no opioids, steroids \\
\hline
\end{tabular}

TABLE 3: The overview of the six patients who had Edmonton Symptom Assessment System (ESAS) scores $<4$ for all the items.

PS: performance status, NSCLC: non-small cell lung cancer, CTx: chemotherapy.

Two patients reported scores not exceeding three for all items. These patients had excellent performance status too. None of the six patients (6\%) with relatively low ESAS scores received care by the hospital's multidisciplinary palliative team. Only one was using opioid analgesics. The median survival for this small subset of six patients was six months, identical to the result for all the patients with higher symptom burden (Figure 1, $\mathrm{p}=0.62$ ). 


\section{Cureus}

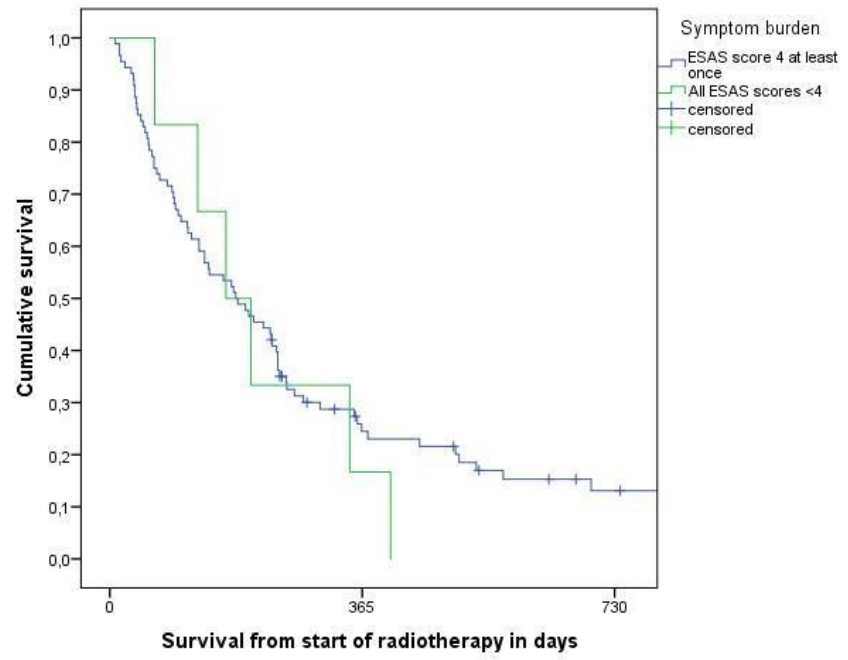

FIGURE 1: The actuarial overall survival after the radiotherapy.

\section{Discussion}

The present study was performed as an extension of a previous one [16] and examined the impact of low ESAS symptom-burden of survival after the palliative radiotherapy. Previously, we performed standard uni- and multivariate- analyze where each ESAS item was dichotomized by the median. The multivariate model showed that appetite and pain were associated with survival, in addition to the performance status, administration of the systemic treatment and other variables. Other studies have also suggested that certain ESAS items influenced survival outcomes [9-10]. However, the results were not identical. Currently, these patient-reported symptoms are not included in commonly employed prognostic models, e.g., for brain metastasis and lung cancer [13-15, 17-18].

Other methodological approaches than dichotomization by median exist too. We hypothesized that the patients with minimal or moderate total symptom burden might have better overall survival than those with at least one higher symptom score. Therefore, we identified the patients with the score zero for all items (no symptoms), at least one item with score one-two (minimal symptoms), and at least one item with the score three (moderate symptoms). Surprisingly, few patients (6\%) fell into these categories. Therefore, our survival analysis had limited statistical power. The six patients with low symptom burden were not among the group of long-term survivors. The median survival was similar in the two subsets of the patients with different ESAS scores. It was interesting to note that the patients with low scores were a heterogeneous group, however, most of them had a performance status zero-one and received the systemic therapy, rather than the radiation alone. As one might expect, these six patients were not managed by our multidisciplinary palliative team and only one of them used opioid analgesics. In other words, the low symptom burden was also reflected in the general patterns of care, and the different data were consistent. 
The ESAS information may be used to triage the patients with a relatively severe symptom burden to different palliative measures. However, this tool is less comprehensive than the quality of life questionnaires [19-20] and lacks potentially relevant domains, such as hematuria, which was present in one of our patients with otherwise negligible symptoms. Future studies that aim at identification of the patients with favorable prognosis should, therefore, focus on other predictors, e.g., performance status, primary cancer type and extent of metastasis. Regarding the patient-reported symptoms, the methodology used in the present study appears less promising than employing median scores or scores $\geqslant 4$, i.e., previously suggested approaches $[9,16]$.

\section{Conclusions}

The proportion of the patients with ESAS scores zero-three throughout the questionnaire was $6 \%$, which resulted in the limited statistical power for the survival comparisons. The survival outcomes were similar. Before PRT, $94 \%$ of the patients reported at least one ESAS item of severity four-10. The symptoms not included in the questionnaire, e.g., hematuria, might result in the erroneous assignment to the low-symptom-burden group and obscure the prognostic impact of the low ESAS symptom burden.

\section{Additional Information}

\section{Disclosures}

Human subjects: Consent was obtained by all participants in this study. REK, Nordland issued approval Not applicable. As a retrospective analysis of the standard clinical care, no approval from the Regional Committee for Medical and Health Research Ethics was necessary. Similarly, no approval from the Norwegian Social Science Database (NSD) had to be obtained. Animal subjects: All authors have confirmed that this study did not involve animal subjects or tissue. Conflicts of interest: In compliance with the ICMJE uniform disclosure form, all authors declare the following: Payment/services info: All authors have declared that no financial support was received from any organization for the submitted work. Financial relationships: All authors have declared that they have no financial relationships at present or within the previous three years with any organizations that might have an interest in the submitted work. Other relationships: All authors have declared that there are no other relationships or activities that could appear to have influenced the submitted work.

\section{References}

1. Bruera E, Kuehn N, Miller MJ, et al.: The Edmonton symptom assessment system (ESAS): A simple method for the assessment of palliative care patients. J Palliat Care. 1991, 7:6-9.

2. Körner P, Ehrmann K, Hartmannsgruber J, et al.: Patient-reported symptoms during radiotherapy: Clinically relevant symptom burden in patients treated with palliative and curative intent. Strahlenther Onkol. 2017, 193:570-577. 10.1007/s00066-017-1146-5

3. Zeng L, Koo K, Zhang L, et al.: Fatigue in advanced cancer patients attending an outpatient palliative radiotherapy clinic as screened by the Edmonton symptom assessment system. Support Care Cancer. 2012, 20:1037-1042. 10.1007/s00520-011-1179-8

4. Fan G, Hadi S, Chow E: Symptom clusters in patients with advanced-stage cancer referred for palliative radiation therapy in an outpatient setting. Support Cancer Ther. 2007, 4:157-162. 10.3816/SCT.2007.n.010

5. Nieder C, Dalhaug A, Pawinski A, et al.: Palliative radiotherapy with or without additional care by a multidisciplinary palliative care team in patients with newly diagnosed cancer: A retrospective matched pairs comparison. Radiat Oncol. 2015, 7:61. 10.1186/s13014-015-03650

6. Nieder C, Tollåli T, Haukland E, et al.: Impact of early palliative interventions on the outcomes of care for patients with non-small cell lung cancer. Support Care Cancer. 2016, 24:4385-4391. 10.1007/s00520-016-3278-z 
7. Ganesh V, Zhang L, Chan S, et al.: An update in symptom clusters using the Edmonton Symptom Assessment System in a palliative radiotherapy clinic. Support Care Cancer. 2017, 25:3321-3327. 10.1007/s00520-017-3749-x

8. Bedard G, Zeng L, Zhang L, et al.: Minimal clinically important differences in the Edmonton Symptom Assessment System in patients with advanced cancer. J Pain Symptom Manage. 2013, 46:192-200. 10.1016/j.jpainsymman.2012.07.022

9. Chow E, Abdolell M, Panzarella T, et al.: Validation of a predictive model for survival in metastatic cancer patients attending an outpatient palliative radiotherapy clinic. Int J Radiat Oncol Biol Phys. 2009, 73:280-287. 10.1016/j.ijrobp.2008.03.019

10. Zeng L, Zhang L, Culleton S, et al.: Edmonton symptom assessment scale as a prognosticative indicator in patients with advanced cancer. J Palliat Med. 2011, 14:337-342. 10.1089/jpm.2010.0438

11. Lefkowits CW, Rabow ME, Sherman AK, et al.: Predictors of high symptom burden in gynecologic oncology outpatients: Who should be referred to outpatient palliative care? Gynecol Oncol. 2014, 132:698-702. 10.1016/j.ygyno.2014.01.038

12. Rhondali W, Yennurajalingam S, Ferrer J, et al.: Association between supportive care interventions and patient self-reported depression among advanced cancer outpatients. Support Care Cancer. 2014, 22:871-879. 10.1007/s00520-013-2042-x

13. Nieder C, Norum J, Hintz M, et al.: Short survival time after palliative whole brain radiotherapy: Can we predict potential overtreatment by use of a nomogram? J Cancer. 2017, 8:1525-1529. 10.7150/jca.18600

14. Nieder C, Mannsåker B, Dalhaug A, et al.: The Glasgow prognostic score: Useful information when prescribing palliative radiotherapy. Mol Clin Oncol. 2017, 6:811-816.

15. Nieder C, Andratschke N, Angelo K, et al.: Development of a score predicting survival after palliative reirradiation. J Oncol. 2014, 2014:1-7. 10.1155/2014/128240

16. Nieder C, Kämpe T, Mannsåker B, et al.: Improvement of models for survival prediction through inclusion of patient-reported symptoms. Radiother Oncol. 2017, 123:44-45. 10.1016/S0167-8140(17)30531-5

17. Nieder C, Hintz M, Oehlke O, et al.: Validation of the graded prognostic assessment for lung cancer with brain metastases using molecular markers (lung-molGPA). Radiat Oncol. 2017, 12:107. 10.1186/s13014-017-0844-6

18. Nieder C, Tollåli T, Haukland E, et al.: External validation of a prognostic score for patients receiving palliative thoracic radiotherapy for lung cancer. Clin Lung Cancer. 2017, 18:297301. 10.1016/j.cllc.2017.01.006

19. Bouazza YB, Chiairi I, El Kharbouchi O, et al.: Patient-reported outcome measures (PROMs) in the management of lung cancer: A systematic review. Lung Cancer. 2017, 113:140-151. 10.1016/j.lungcan.2017.09.011

20. Van der Weijst L, Surmont V, Schrauwen W, et al.: Systematic literature review of healthrelated quality of life in locally-advanced non-small cell lung cancer: has it yet become stateof-the-art?. Crit Rev Oncol Hematol. 2017, 119:40-49. 10.1016/j.critrevonc.2017.09.014 